\title{
Sexual satisfaction in women and its predictors
}

\author{
Original \\ Ihab Younis ${ }^{1}$, Doaa M. El-Habbaq ${ }^{1}$, Mona A. Al-Awady', Amal Mostafa ${ }^{1}$ \\ Article \\ ${ }^{1}$ Department of Dermatology, Venereology and Andrology, ${ }^{2}$ Department of Community \\ Medicine, Faculty of Medicine, Banha University.
}

\begin{abstract}
Introduction: Sexual satisfaction is a multidimensional experience involving thoughts, feelings, personal and sociocultural attitudes and beliefs, combined with biological factors.

Aim of the Study: The present study aimed to assess the degree of sexual satisfaction and its predictors in a convenience sample of married Egyptian women.

Materials and Methods: 302 married women were recruited for this study. The tool used was a self-report questionnaire designed by the authors with the help of the COSECON survey. The questionnaire included questions about demographic data, sexual satisfaction, sexual activities e.g. frequency of coitus, obtaining lubrication and orgasm.

Results: The degree of sexual satisfaction was as follows: $57.9 \%$ highly satisfied, $22.2 \% \%$ moderately satisfied and $19.9 \%$ dissatisfied. The main predictors of satisfaction were: age, coital frequency, spontaneous desire, lubrication and the ability to reach orgasm. Foreplay duration and method, duration of marriage, residence and educational level were all related to sexual satisfaction.

Conclusion: Sexual medicine counselors may benefit from the present work in dealing with their female clients. Determining the degree of sexual satisfaction plus looking for its predictors are important in helping couples with a problematic sexual relation.
\end{abstract}

Key Words: Egyptian, predictors, satisfaction, women.

Received: 25 April 2019, Accepted: 04 May 2019

Corresponding Author: Ihab Younis, MD, Department of Dermatology, Venereology and Andrology, Faculty of Medicine, Benha University, Benha, Egypt, Tel.: +201017186419, E-mail: ihabyounis@hotmail.com

ISSN: 2090-6048, March 2019, Vol. 9, No. 1

\section{INTRODUCTION}

Holmberg and Blair ${ }^{[1]}$ define sexual satisfaction as 'an overall, global appraisal of the quality of one's sex life.'

Sexual satisfaction is difficult to measure. Some authors have tried to improve the usually poor conceptualization and weak measurements, yet only a few of them have developed specific instruments to deal with sexual satisfaction $^{[2]}$

Sexual satisfaction has been shown to be related to the characteristics and behavior of the partner, emotions, and sexual behaviors as well as to social background factors. Sexual behaviors connected to sexual satisfaction included frequent intercourse, oral-genital sex, experimental lovemaking, and orgasm ${ }^{[3]}$.

Satisfaction with one's sex life is a significant factor that affects quality of life. It has been suggested that a satisfactory sex life leads to better psychological wellbeing. Past research suggests multiple linkages between sexual satisfaction, relationship quality, and personal knowledge and values ${ }^{[4]}$.

\section{AIM OF THE STUDY}

Most research has focused on western populations, but whether their findings apply to other societies remains unclear $^{[5]}$. So, this study was conducted with the aim to evaluate the prevalence and predictors of sexual satisfaction in a sample of married Egyptian women.

\section{MATERIALS AND METHODS}

This cross-sectional study started after taking the approval of the Dermatology and Andrology Department and The Medical Ethics Committee in Benha University.

The participants were 302 married women attending the outpatient clinic in Benha University Hospital and the Maternal and Childhood Care Units in Toukh City during the period from June 2018 to December 2018. They were informed about the nature of the study and were asked to participate before taking their informed consent. They were married women with regular sexual intercourse. Women with any medical conditions affecting female sexuality, for example, neuropsychiatric diseases were 
excluded from the study. Also, women who currently have no marital sexual activity, for example, due to a sexually dysfunctional husband were not included in the study.

The tool used in this study was a self-report questionnaire designed by the authors with the help of the COSECON survey ${ }^{[6]}$. To ensure that all gathered information will be kept confidential and the subject will be anonymous, each questionnaire was handed in an open envelope and after the participant filled it, she sealed the envelope and put it in a basket containing other sealed envelopes.

The questionnaire included questions about the following items:

(1) Epidemiological data: age, the educational level, etc.

(2) Assessment of sexual satisfaction.

(3) Female sexual functions,for example, frequency of intercourse, spontaneous desire to have sex, lubrication, orgasm, and overall sexual satisfaction.

\section{Data management}

The clinical data were recorded on a report form. These data were tabulated and analyzed using the computer program statistical package for the social sciences (SPSS) version 20 (IBM Corporation, Chicago, Illinois, USA).

\section{Descriptive data}

Descriptive statistics were calculated for the data in the form of frequency and distribution for qualitative data.

\section{Analytical statistics}

In the statistical comparison between the different groups, the significance of difference was tested using one of the following tests:

Intergroup comparison of categorical data was performed using $\chi 2$-test and Fisher's exact test.

A $P$ value less than 0.05 was considered statistically significant in all analyses.

\section{RESULTS}

Out of the 350 distributed questionnaires, 302 were completely and adequately filled with a rejection rate of $13.7 \%$.

Participants estimating that their overall degree of sexual satisfaction was more than $50 \%$ (highly satisfied) were 175 (57.9\%) women, those with an overall degree of sexual satisfaction of less than $50 \%$ (moderately satisfied) were 67 (22.2\%) women, while the number of dissatisfied women was 60 representing $19.9 \%$ of the whole sample.
The age range of the participants was 18-55 years, most of them (47.4\%) belonged to the age group of 20-29 years. The most common educational level was a university degree (75.2\%). Most participants had a job (83.8\%) and were living in rural areas $(51.7 \%)$ (Table 1$)$.

Table 2 indicates that sexual satisfaction decreased in relation to age as high sexual satisfaction decreased from $60 \%$ in the $20-29$ years age group to become $11.1 \%$ in the more than 50 years age group. Also, lubrication attainment and orgasm showed statistically significant decline with age.

The relation between sexual activity and the degree of sexual satisfaction is shown in Table 3. Frequency of intercourse was lower in women reporting dissatisfaction of their sexual life. Also, frequency of spontaneous sexual desire seems to be less in dissatisfied women as compared with highly satisfied ones.

The largest sector of dissatisfied participants had problems in lubrication and obtaining orgasm (33.3 and $48.4 \%$, respectively) as shown in Table 3 . The same table indicates that dyspareunia was rarely or almost does not occur in $48.6 \%$ of highly satisfied participants compared with $28.3 \%$ of the dissatisfied group.

There was a high statistically significant relation $(P<0.001)$ between the three degrees of sexual satisfaction regarding some aspects related to spouse. Among the dissatisfied participants, $21.7 \%$ reject husband's proposal to have sex most of the times and when they accept it the reason is mainly to obey God's orders $(38.3 \%)$. This is compared with only $5.7 \%$ of highly satisfied women who reported commonly rejecting husband's sexual requests (Table 4).

Table 4 also shows no statistically significant difference between the three groups regarding suitability of penile size or the most suitable coital position that enables women to have orgasm. But dissatisfied women showed a statistically significant inferiority than highly satisfied concerning foreplay duration and method. Duration of marriage showed an increase in sexual satisfaction after 5-10 years and then it showed a steady decline in the three groups.

Sexual dissatisfaction was more commonly reported by women resident in rural areas $(25.6 \%)$ compared with urban areas $(13.7 \%)$. Also, there was a high statistically significant difference $(P<0.001)$ between the three degrees of sexual satisfaction and educational level. High satisfaction occurred in $65.2 \%$ of participants with a university degree, while dissatisfaction was the most common among participants who can only read and write and those who finished secondary school (58.3 and 41.3, respectively; Table 5). 
Table 1: Demographic characteristics of the studied women $(n=302)$.

\begin{tabular}{|c|c|c|c|}
\hline- & & $\mathrm{n}$ & $\%$ \\
\hline \multirow{5}{*}{ Age } & $<20$ & 1 & 0.3 \\
\hline & $20-29$ & 143 & 47.4 \\
\hline & $30-39$ & 119 & 39.4 \\
\hline & $40-49$ & 30 & 9.9 \\
\hline & 50or more & 9 & 3.0 \\
\hline \multirow{3}{*}{ Educational Level } & Can read and write & 12 & 4.0 \\
\hline & Finished secondary school & 63 & 20.9 \\
\hline & Have a university degree & 227 & 75.2 \\
\hline \multirow{2}{*}{ Do you have a job? } & Yes & 253 & 83.8 \\
\hline & No & 49 & 16.2 \\
\hline \multirow{2}{*}{ Residence } & Rural & 156 & 51.7 \\
\hline & Urban & 146 & 48.3 \\
\hline
\end{tabular}

Table 2: Relation between age and sexual satisfaction

\begin{tabular}{|c|c|c|c|c|c|c|c|c|c|c|c|c|c|}
\hline & \multirow{3}{*}{-} & \multicolumn{10}{|c|}{ Age } & \multirow{3}{*}{\multicolumn{2}{|c|}{$\begin{array}{l}\text { Statistical } \\
\text { Test }\end{array}$}} \\
\hline & & \multicolumn{2}{|c|}{$<20$} & \multicolumn{2}{|c|}{$20-29$} & \multicolumn{2}{|c|}{$30-39$} & \multicolumn{2}{|c|}{$40-49$} & \multicolumn{2}{|c|}{50 or more } & & \\
\hline & & $\mathrm{n}$ & $\%$ & $\mathrm{n}$ & $\%$ & $\mathrm{n}$ & $\%$ & $\mathrm{n}$ & $\%$ & $\mathrm{n}$ & $\%$ & & \\
\hline \multirow{3}{*}{ Sexual satisfaction } & Highly satisfied & 0 & 0.0 & 86 & 60.1 & 75 & 63.0 & 13 & 43.3 & 1 & 11.1 & \multirow{3}{*}{28.63} & \multirow{3}{*}{$<0.001 *$} \\
\hline & Moderately satisfied & 0 & 0.0 & 32 & 22.4 & 28 & 23.5 & 5 & 16.7 & 2 & 22.2 & & \\
\hline & Dissatisfied & 1 & 100 & 25 & 17.5 & 16 & 13.4 & 12 & 40.0 & 6 & 66.7 & & \\
\hline
\end{tabular}

$* p<0.001$ (highly significant).

Table 3: Effect of some aspects of sexual activity on sexual satisfaction.

\begin{tabular}{|c|c|c|c|c|c|c|c|c|c|}
\hline \multirow{2}{*}{-} & & \multicolumn{2}{|c|}{ Highly satisfied } & \multicolumn{2}{|c|}{ Moderately satisfied } & \multicolumn{2}{|c|}{ Dissatisfied } & \multirow{2}{*}{$\mathrm{x}^{2}$ test } & \multirow{2}{*}{$P$ value } \\
\hline & & $\mathrm{n}$ & $\%$ & $\mathrm{n}$ & $\%$ & $\mathrm{n}$ & $\%$ & & \\
\hline \multirow{5}{*}{ Coital frequency } & Daily & 11 & 6.3 & 2 & 3.0 & 1 & 1.7 & \multirow{5}{*}{$\mathrm{FET}=51.92$} & \multirow{5}{*}{$<0.001 *$} \\
\hline & 2-3 times /week & 99 & 56.6 & 21 & 31.3 & 33 & 55.0 & & \\
\hline & Once /week & 62 & 35.4 & 31 & 46.3 & 11 & 18.3 & & \\
\hline & Once/M & 1 & 0.6 & 9 & 13.4 & 6 & 10.0 & & \\
\hline & $<$ than that & 2 & 1.1 & 4 & 6.0 & 9 & 15.0 & & \\
\hline \multirow{6}{*}{$\begin{array}{l}\text { Spontaneous sexual } \\
\text { desire }\end{array}$} & Daily & 5 & 2.9 & 3 & 4.5 & 2 & 3.3 & \multirow{6}{*}{$\mathrm{FET}=29.74$} & \multirow{6}{*}{$0.001 *$} \\
\hline & once / day & 11 & 6.3 & 7 & 10.4 & 2 & 3.3 & & \\
\hline & 2-3 times /week & 39 & 22.3 & 6 & 9.0 & 10 & 16.7 & & \\
\hline & Once /week & 66 & 37.7 & 13 & 19.4 & 18 & 30.0 & & \\
\hline & once / month & 26 & 14.9 & 12 & 17.9 & 5 & 8.3 & & \\
\hline & $<$ than that & 28 & 16.0 & 26 & 38.8 & 23 & 38.3 & & \\
\hline
\end{tabular}


Younis et al.

\begin{tabular}{|c|c|c|c|c|c|c|c|c|c|}
\hline \multirow{4}{*}{ Lubrication } & Always & 81 & 46.3 & 7 & 10.4 & 11 & 18.3 & \multirow{4}{*}{58.11} & \multirow{4}{*}{$<0.001^{*}$} \\
\hline & $>1 / 2$ times & 62 & 35.4 & 24 & 35.8 & 16 & 26.7 & & \\
\hline & $<1 / 2$ times & 21 & 12.0 & 18 & 26.9 & 13 & 21.7 & & \\
\hline & $\begin{array}{c}\text { Rarely or } \\
\text { almost never }\end{array}$ & 11 & 6.3 & 18 & 26.9 & 20 & 33.3 & & \\
\hline \multirow{4}{*}{ Orgasm } & Always & 36 & 20.6 & 3 & 4.5 & 3 & 5.0 & \multirow{4}{*}{111.63} & \multirow{4}{*}{$<0.001 *$} \\
\hline & $>1 / 2$ times & 100 & 57.1 & 7 & 10.4 & 11 & 18.3 & & \\
\hline & $<1 / 2$ times & 23 & 13.1 & 33 & 49.3 & 17 & 28.3 & & \\
\hline & $\begin{array}{c}\text { Rarely or } \\
\text { almost never }\end{array}$ & 16 & 9.1 & 24 & 35.8 & 29 & 48.3 & & \\
\hline \multirow{4}{*}{$\begin{array}{l}\text { Pelvic congestion } \\
\text { symptoms }\end{array}$} & Always & 12 & 6.9 & 8 & 11.9 & 9 & 15.0 & \multirow{4}{*}{10.02} & \multirow{4}{*}{0.12} \\
\hline & $>1 / 2$ times & 26 & 14.9 & 15 & 22.4 & 11 & 18.3 & & \\
\hline & $<1 / 2$ times & 67 & 38.3 & 28 & 41.8 & 18 & 30.0 & & \\
\hline & $\begin{array}{l}\text { Rarely or } \\
\text { almost never }\end{array}$ & 70 & 40.0 & 16 & 23.9 & 22 & 36.7 & & \\
\hline \multirow{4}{*}{ Dyspareunia } & Always & 13 & 7.4 & 11 & 16.4 & 14 & 23.3 & \multirow{4}{*}{26.54} & \multirow{4}{*}{$<0.001 *$} \\
\hline & $>1 / 2$ times & 29 & 16.6 & 11 & 16.4 & 17 & 28.3 & & \\
\hline & $<1 / 2$ times & 48 & 27.4 & 27 & 40.3 & 12 & 20.0 & & \\
\hline & $\begin{array}{c}\text { Rarely or } \\
\text { almost never }\end{array}$ & 85 & 48.6 & 18 & 26.9 & 17 & 28.3 & & \\
\hline
\end{tabular}

${ }^{*} p<0.01$ highly significant.

Table 4: Spouse factors and sexual satisfaction.

\begin{tabular}{|c|c|c|c|c|c|c|c|c|c|}
\hline \multirow{2}{*}{ - } & & \multicolumn{2}{|c|}{ Highly satisfied } & \multicolumn{2}{|c|}{ Moderately satisfied } & \multicolumn{2}{|c|}{ Dissatisfied } & \multirow{2}{*}{$\mathrm{x}^{2}$ test } & \multirow{2}{*}{$P$ value } \\
\hline & & $\mathrm{n}$ & $\%$ & $\mathrm{n}$ & $\%$ & $\mathrm{n}$ & $\%$ & & \\
\hline \multirow{4}{*}{$\begin{array}{l}\text { Response to } \\
\text { husband request to } \\
\text { have sex }\end{array}$} & Always approve & 59 & 33.7 & 10 & 14.9 & 15 & 25.0 & \multirow{4}{*}{27.48} & \multirow{4}{*}{$<0.001^{*}$} \\
\hline & Approve $>1 / 2$ times & 84 & 48.0 & 27 & 40.3 & 20 & 33.3 & & \\
\hline & Approve $<1 / 2$ times & 22 & 12.6 & 17 & 25.4 & 12 & 20.0 & & \\
\hline & $\begin{array}{l}\text { Reject most } \\
\text { of times }\end{array}$ & 10 & 5.7 & 13 & 19.4 & 13 & 21.7 & & \\
\hline \multirow{4}{*}{$\begin{array}{lr}\text { Reason } & \text { for } \\
\text { accepting } & \text { husband } \\
\text { request } & \end{array}$} & Obeying god & 23 & 13.1 & 24 & 35.8 & 23 & 38.3 & \multirow{4}{*}{31.3} & \multirow{4}{*}{$<0.001 *$} \\
\hline & Have same desire & 22 & 12.6 & 1 & 1.5 & 5 & 8.3 & & \\
\hline & All of above & 120 & 68.6 & 35 & 52.2 & 27 & 45.0 & & \\
\hline & Other reasons & 10 & 5.7 & 7 & 10.4 & 5 & 8.3 & & \\
\hline \multirow{5}{*}{$\begin{array}{l}\text { Reason for rejecting } \\
\text { husband request }\end{array}$} & No ideal time & 27 & 15.4 & 4 & 6.0 & 13 & 21.7 & \multirow{5}{*}{21.89} & \multirow{5}{*}{$0.005 *$} \\
\hline & Feel tired & 52 & 29.7 & 14 & 20.9 & 12 & 20.0 & & \\
\hline & Lack of desire & 6 & 3.4 & 8 & 11.9 & 4 & 6.7 & & \\
\hline & All of above & 62 & 35.4 & 36 & 53.7 & 26 & 43.3 & & \\
\hline & Other reasons & 28 & 16.0 & 5 & 7.5 & 5 & 8.3 & & \\
\hline \multirow{5}{*}{ Foreplay method } & No foreplay & 3 & 1.7 & 4 & 6.0 & 10 & 16.7 & \multirow{5}{*}{29.58} & \multirow{5}{*}{$<0.001^{*}$} \\
\hline & Verbal method & 9 & 5.1 & 2 & 3.0 & 6 & 10.0 & & \\
\hline & Physical method & 71 & 40.6 & 21 & 31.3 & 23 & 38.3 & & \\
\hline & verbal/ physical & 91 & 52.0 & 38 & 56.7 & 19 & 31.7 & & \\
\hline & Other & 1 & 0.6 & 2 & 3.0 & 2 & 3.3 & & \\
\hline
\end{tabular}




\begin{tabular}{|c|c|c|c|c|c|c|c|c|c|}
\hline \multirow{2}{*}{ Forplay duration } & Enough & 146 & 83.4 & 31 & 46.3 & 32 & 53.3 & \multirow{2}{*}{40.24} & \multirow{2}{*}{$<0.001 *$} \\
\hline & Not enough & 29 & 16.6 & 36 & 53.7 & 28 & 46.7 & & \\
\hline \multirow{3}{*}{$\begin{array}{l}\text { Appreciation of size } \\
\text { of penis }\end{array}$} & Suitable & 166 & 94.9 & 54 & 80.6 & 47 & 78.3 & \multirow{3}{*}{17.05} & \multirow{3}{*}{$0.002 *$} \\
\hline & Hoping larger & 6 & 3.4 & 9 & 13.4 & 9 & 15.0 & & \\
\hline & Hoping smaller & 3 & 1.7 & 4 & 6.0 & 4 & 6.7 & & \\
\hline \multirow{6}{*}{$\begin{array}{l}\text { Preferred position } \\
\text { to reach orgasm }\end{array}$} & Husband on top & 83 & 47.4 & 31 & 46.3 & 24 & 40.0 & \multirow{6}{*}{$\mathrm{FET}=24.83$} & \multirow{6}{*}{$0.006^{*}$} \\
\hline & Woman on top & 36 & 20.6 & 6 & 9.0 & 5 & 8.3 & & \\
\hline & Rear entry & 20 & 11.4 & 7 & 10.4 & 5 & 8.3 & & \\
\hline & Side to side ent. & 6 & 3.4 & 0 & 0.0 & 1 & 1.7 & & \\
\hline & All of above & 13 & 7.4 & 6 & 9.0 & 9 & 15.0 & & \\
\hline & $\begin{array}{l}\text { No preferred } \\
\text { position }\end{array}$ & 17 & 9.7 & 17 & 25.4 & 16 & 26.7 & & \\
\hline \multirow{5}{*}{$\begin{array}{l}\text { Duration } \quad \text { of } \\
\text { marriage }\end{array}$} & $<5$ years & 52 & 29.7 & 22 & 32.8 & 13 & 21.7 & \multirow{5}{*}{28.1} & \multirow{5}{*}{$<0.001^{*}$} \\
\hline & $5-10$ years & 90 & 51.4 & 25 & 37.3 & 17 & 28.3 & & \\
\hline & $11-15$ years & 17 & 9.7 & 9 & 13.4 & 12 & 20.0 & & \\
\hline & $16-30$ years & 15 & 8.6 & 9 & 13.4 & 13 & 21.7 & & \\
\hline & More than 30 & 1 & 0.6 & 2 & 3.0 & 5 & 8.3 & & \\
\hline
\end{tabular}

${ }^{*} p<0.01$ highly significant.

Table 5: Effect of residence, educational level and having a job on sexual satisfaction.

\begin{tabular}{|c|c|c|c|c|c|c|c|c|c|c|c|c|c|c|c|}
\hline & & \multicolumn{4}{|c|}{ Residence } & \multicolumn{6}{|c|}{ Educational Level } & \multicolumn{4}{|c|}{ Job } \\
\hline & & \multicolumn{2}{|c|}{ Rural } & \multicolumn{2}{|c|}{ Urban } & \multicolumn{2}{|c|}{ Read and write } & \multicolumn{2}{|c|}{$\begin{array}{c}\text { Finished 2ry } \\
\text { school }\end{array}$} & \multicolumn{2}{|c|}{$\begin{array}{c}\text { Have a } \\
\text { university } \\
\text { degree }\end{array}$} & \multicolumn{2}{|c|}{ Have a job } & \multicolumn{2}{|c|}{$\begin{array}{l}\text { Have } \\
\text { no job }\end{array}$} \\
\hline & & $\mathrm{n}$ & $\%$ & $\mathrm{n}$ & $\%$ & $\mathrm{n}$ & $\%$ & $\mathrm{n}$ & $\%$ & $\mathrm{n}$ & $\%$ & $\mathrm{n}$ & $\%$ & $\mathrm{n}$ & $\%$ \\
\hline & $\begin{array}{l}\text { Highly } \\
\text { satisfied }\end{array}$ & 88 & 56.4 & 87 & 59.6 & 4 & 33.3 & 23 & 36.5 & 148 & 65.2 & 144 & 56.9 & 31 & 63.3 \\
\hline \multirow[t]{2}{*}{$\begin{array}{l}\text { Sexual } \\
\text { satisaction }\end{array}$} & $\begin{array}{c}\text { Moderately } \\
\text { satisfied }\end{array}$ & 28 & 17.9 & 39 & 26.7 & 1 & 8.3 & 14 & 22.2 & 52 & 22.9 & 59 & 23.3 & 8 & 16.3 \\
\hline & Dissatisfied & 40 & 25.6 & 20 & 13.7 & 7 & 58.3 & 26 & 41.3 & 27 & 11.9 & 50 & 19.8 & 10 & 20.4 \\
\hline $\begin{array}{l}\text { Statistical } \\
\text { test }\end{array}$ & $\mathrm{x}^{2}$ Test & \multicolumn{4}{|c|}{8.16} & \multicolumn{6}{|c|}{$\mathrm{FET}=40.13$} & \multicolumn{4}{|c|}{1.2} \\
\hline \multicolumn{2}{|c|}{$P$ test } & \multicolumn{4}{|c|}{$0.017^{*}$} & \multicolumn{6}{|c|}{$<0.001 * *$} & \multicolumn{4}{|c|}{0.55} \\
\hline
\end{tabular}

${ }^{*} p>0.05$ significant $* * p<0.01$ highly significant.

\section{DISCUSSION}

The WHO considered sexual satisfaction as an important component of sexual health, a sexual right, and an outcome of sexual well-being ${ }^{[7]}$.

Sexually dissatisfied women in this study represented $19.9 \%$ of the whole sample. A 2017 survey of 2002 women aged 30 to 80 years in $\mathrm{UK}^{[8]}$ revealed that one woman in five is unhappy with her sex life and only $17 \%$ of women say they are very satisfied.The Global Better Sex Survey ${ }^{[9]}$ collected data from 12563 respondents $(m e n=6291$, women $=6272$ ) from 27 countries. Among the assessed aspects of sexual life was satisfaction with sex life. Very satisfied women comprised $66 \%$ of the sample, $39 \%$ of women were satisfied while $17 \%$ were less satisfied. On the other hand, among 3163 women, aged 18-69 years surveyed in Chile $7.8 \%$ reported that they are sexually dissatisfied ${ }^{[6]}$.

This study noticed a decline in sexual satisfaction, as well as obtaining and maintaining lubrication and orgasm, with aging. Physiologically, lubrication is delayed and reduced in quantity due to a decline in estrogen with advanced age. The decrease in vaginal vasocongestion and lubrication may contribute to dryness of the vagina 
together with vaginal atrophic changes which may make intercourse painful. Laumann et al. ${ }^{[10]}$ carried out a survey involving 13882 women and 13618 men, aged 40-80 years, in 29 countries, representing many world regions. They reported a decrease in women's satisfaction with their sexual behavior with increasing age. Similar results were reported by Lindau et al. ${ }^{[1]}$.

A higher coital frequency was a predictor of sexual satisfaction in our participants. Other predictors were a good frequency of spontaneous sexual desire, obtaining lubrication, frequent orgasm, and infrequent occurrence of dyspareunia. In a Chinese study ${ }^{[12]}$, frequency of intercourse, caressing during sex, and frequency of wife's orgasm increased sexual satisfaction. The link between behavioral aspects of sex life and sexual satisfaction appeared in the work of Parish et al. ${ }^{[5]}$ where a variety of sexual techniques, frequency of intercourse, and frequency of orgasm were all associated with sexual satisfaction. Achieving orgasm was found to be an important predictor of sexual satisfaction, especially for women ${ }^{[13]}$.

Relation with husband seems to be an important indicator of sexual satisfaction. Among dissatisfied women, $21.7 \%$ rejected husband's proposal to have sex most of the times as compared with $5.7 \%$ of highly satisfied women. And even when dissatisfied women accept this proposal it is because of obeying God's orders (38.3\% in dissatisfied compared with $13.1 \%$ in highly satisfied women). The reasons for rejecting to have sex with the husband among dissatisfied women included absence of foreplay (16.7\%) or its short duration (46.7\%). To explore issues that heterosexual women have concerning their sex life and desire toward their male partner, Nagao et al. ${ }^{[14]}$ conducted an online survey on actual sex life and sexual quality of life. Survey participants included 5665 women who were 20 years of age and older, living in or near Tokyo and have a male sex partner. Their results showed that women tend to desire a longer duration of foreplay and afterplay than they are actually experiencing.Also, their results showed that women consider foreplay and afterplay more meaningful than intercourse and/or sexual positions. Hisasue et al. ${ }^{[15]}$ conducted a survey of 8956 Japanese women and reported similar findings.

Although highly satisfied, moderately satisfied, and sexually dissatisfied women in this study revealed no concern about their husbands' penile size, $15 \%$ of unsatisfied women hoped their husbands would have got a larger penis compared with $3.4 \%$ of highly satisfied women. Shaeer et $a l^{[16]}$ conducted the Global Online Sexuality Surveywhich is an internet-based survey investigating various aspects of male and female sexual function. To study the effect of penis girth versus length on female sexual satisfaction, Eisenman ${ }^{[17]}$ surveyed 50 sexually active female undergraduate students by asking which is more important and felt better for their sexual satisfaction, penis girth or length. None reported they did not know, or that girth and length were equally satisfying.
A large majority (45 of 50) reported girth was more important $(P<0.001)$. Eisenman ${ }^{[17]}$ stated that 'maybe Masters and Johnson ${ }^{[18]}$ were wrong about penis size having little or no physiological effect on women's sexual satisfaction. However, this data cannot provide a final answer, since they are based on self-reports of women surveyed about penis length versus girth, and their sexual satisfaction. The results reflect either a psychological preference or a true physiological reality.'

It was noticed, in this study, that satisfaction increases after the first 5 years,then it steadily declines with increase in marriage duration. Schmiedeberg and Schröder ${ }^{[19]}$ found a positive development of sexual satisfaction in the first year of a relationship, followed by a steady decline. $\mathrm{Liu}^{[20]}$ assumed that increase in sexual satisfaction in the beginning of a relationship is due to a learning effect,then the habituation effect leads to a decline in satisfaction with increase in relationship duration.

Dissatisfied women residing in rural areas were more than those living in urban areas (25.6 vs. $13.7 \%$, respectively). This may be due to the higher rate of female genital cutting in rural areas of Egypt ${ }^{[21]}$. In rural areas, culture and ideology can have a significant impact on beliefs and attitudes of people. In some rural societies, marital relationship is done as a task and not an enjoyable action and this can result in reduction of sexual desire and sexual satisfaction ${ }^{[22]}$.

Educational level was significantly related to our participants' sexual satisfaction. The percentage of dissatisfied women who can only read and write was four times larger than those with a university degree. Barrientos and Páez ${ }^{[6]}$ analyzed psychosocial variables of sexual satisfaction and showed that high educational level, marital status, and high socioeconomic levels were significantly associated with sexual satisfaction in women but not in men.

\section{LIMITATION OF THE STUDY}

Illiterate women were excluded from this study to ensure complete privacy during filling the questionnaire; however, this exclusion makes the results of this study not representing a large proportion of Egyptian women. Also, many menopausal women refused to answer the questionnaire; this made the results belonging to sexual satisfaction predictors in menopausal women less accurate.

\section{CONCLUSION}

Age had a negative impact as a predictor of sexual satisfaction in this sample. On the other hand, high educational level and urban residence are associated with a high degree of female sexual satisfaction. There is a positive relation between sexual satisfaction and some aspects of sexual activity, for example, coital frequency, frequency of spontaneous desire, frequency to attain and 
maintain lubrication, and frequency of reaching orgasm. An adequate foreplay including manual genital stimulation is a strong predictor for sexual satisfaction in women.

\section{CONFLICT OF INTEREST}

There are no conflicts of interest.

\section{REFERENCES}

1. HolmbergD, BlairKL. Sexual desire, communication, satisfaction, and preferences of men and women in same-sex versus mixed-sex relationships. J Sex Res2009; 46:57-66.

2. MazoGZ, CardosoFL. Sexual satisfaction and correlates among elderly Brazilians. Arch Gerontol Geriatr2011; 52:223-227.

3. Haavio-MannilaE, KontulaO. Correlates of increased sexual satisfaction. Arch Sex Behav 1997; 26:399-419.

4. DijkstraP, BareldsDP. Women, sex and modern society: the sex lives of readers of a Dutch women's magazine. Int J Sex Health2011; 23:35-47.

5. ParishWL, LuoY, StolzenbergR, LaumannEO, FarrerG, PanS. Sexual practices and sexual satisfaction: a population based study of Chinese urban adults. Arch Sex Behav2007; 36:5-20.

6. BarrientosJE, PáezD. Psychosocial variables of sexual satisfaction in Chile. J Sex Marital Ther 2006; 32:351-368.

7. PascoalPM, NarcisoID, PereiraNM. What is sexual satisfaction? Thematic analysis of lay people's definitions. J Sex Res2014; 51:22-30.

8. BorlandS. Revealed, fifth of women unhappy with sex lives. Available at:https://www.iol. co.za/lifestyle/love-sex/sex/revealed-fifthof-women-unhappy-with-sex-lives-9159507. [Accessed 5 December 2018

9. MulhallJ, KingR, GlinaS, HvidstenK. Importance of and satisfaction with sex among men and women worldwide: results of the Global Better Sex Survey. J Sex Med2008; 5:788-795.

10. LaumannEO, NicolosiA, GlasserDB, PaikA, GingellC, MoreiraE, WangT. Sexual problems among women and men aged 40-80 y: prevalence and correlates identified in the Global Study of Sexual Attitudes and Behaviors. Int J Impot Res2005; 17:39-57.

11. LindauST, SchummLP, LaumannEO, LevinsonW, O'MuircheartaighCA, WaiteLJ. A study of sexuality and health among older adults in the United States. N Engl J Med2007; 357:762-774.

12. ZhouMR. A survey of sexual states of married, healthy, reproductive age women. J Psychol Hum Sex1994; 6:15-28.

13. DarlingCA, DavidsonJKSr, CoxRP. Female sexual response and the timing of partner orgasm. J Sex Marital Ther1991; 17:3-21.

14. NagaoK, TaiT, SaigoR, KimuraM, OzakiY, TanakaN, et al.Gaps between actual and desired sex life: web survey of 5,665 Japanese women.J Sex Marital Ther2014; 40:33-42.

15. HisasueSI, KumamotoY, SatoY, MasumoriN, HoritaH, KatoR, et al.Prevalence of female sexual dysfunction symptoms and its relationship to quality of life: a Japanese female cohort study. Urology2005; 65:143-148.

16. ShaeerO, ShaeerK, ShaeerE. The Global Online Sexuality Survey(GOSS): female sexual dysfunction among Internet users in the reproductive age group in the Middle East. J Sex Med2012; 9:411-424.

17. EisenmanR. Penis size: survey of female perceptions of sexual satisfaction. BMC Womens Health 2001; 1:1.

18. MastersWH, JohnsonVE. Human sexual inadequacy. Boston: Little, Brown; 1970.

19. SchmiedebergC, SchröderJ. Does sexual satisfaction change with relationship duration?Arch Sex Behav2016; 45:99-107.

20. LiuCDoes quality of marital sex decline with duration?Arch Sex Behav2003; 32:55-60.

21. El-GibalyO, IbrahimB, MenschBS, ClarkWH. The decline of female circumcision in Egypt: evidence and interpretation. Soc Sci Med2002; 54:205-220.

22. AhmedK, BhugraD. The role of culture in sexual dysfunction. Psychiatry2007; 6:115-120. 